\title{
Experience with the once-yearly histrelin (GnRHa) subcutaneous implant in the treatment of central precocious puberty
}

\author{
Katherine A Lewis \\ Erica A Eugster \\ Department of Pediatrics, Indiana \\ University School of Medicine, \\ Riley Hospital for Children, \\ Indianapolis, USA
}

Correspondence: Katherine A Lewis Department of Pediatrics, Indiana University School of Medicine, Riley Hospital for Children, 702 Barnhill Drive, Indianapolis, IN 46202 USA

$\mathrm{Tel}+\mathrm{I} 3172743889$

Fax +I 3172743882

Email lewis55@iupui.edu

\begin{abstract}
In 2007, a hydrogel histrelin implant was approved for the treatment of children with central precocious puberty (CPP). Children with CPP commonly have reduced height potential due to premature closure of the epiphyseal growth plates from exposure to sex steroids. Gonadotropin-releasing hormone analog (GnRHa) treatment halts puberty and allows for improvement of adult height. A hydrogel implant delivery system utilizing the potent GnRHa, histrelin, was first developed for use in men with prostate cancer. A once yearly histrelin subcutaneous implant was subsequently developed for the treatment of children with CPP. Studies to date have demonstrated safety, tolerability, and effectiveness of this treatment option in patients treated up to 2 years. The most common adverse effects of the implant relate to implant site pain or bruising. Cost of this treatment seems comparable to somewhat higher than the commonly used GnRHa treatment option, depot leuprolide. While long term studies are needed to establish continued efficacy and safety beyond 2 years of treatment, the histrelin implant appears to be an attractive option for GnRHa treatment in patients with CPP.
\end{abstract}

Keywords: central precocious puberty, histrelin, implant, gonadotropin-releasing-hormone analogs

\section{Introduction}

Central precocious puberty (CPP) refers to the early activation of the hypothalamicpituitary-gonadal (HPG) axis leading to secondary sexual characteristics in girls prior to age 7.5 to 8 and in boys prior to age $9 .{ }^{1}$ Children with CPP have advanced skeletal maturity that can result in compromise of final adult height. Gonadotropin-releasing hormone analogs (GnRHa) have been used since the early 1980s to suppress the HPG axis in children with CPP. ${ }^{2}$ Halting puberty in this manner alleviates further bone maturation from sex steroid exposure, resulting in improved predicted adult heights. ${ }^{3}$ Standard treatment of CPP has consisted of depot GnRHa that require injections at approximately 4 -week intervals. ${ }^{4}$ The histrelin subcutaneous implant developed for the treatment of CPP provides an alternative treatment to these frequent injections.

\section{Background}

Histrelin acetate, a potent synthetic GnRHa, has been available in the United States since 1991 for the treatment of central precocious puberty. However, since it required daily administration, it has never been widely used. A hydrogel implant was developed which allowed for the sustained release of histrelin by continuous simple diffusion. By manipulating the water content of the hydrogel capsule, the rate of release can be set to a predetermined amount. ${ }^{5}$

A histrelin hydrogel implant was initially developed for the purpose of obtaining medical castration in men with metastatic prostate cancer. This $50 \mathrm{mg}$ histrelin 
implant was designed to release $60 \mu \mathrm{g}$ of histrelin daily. In an initial study comprising 15 men, a single implant was placed in 8 men and 2 implants were placed in 7 men. Although 4 patients had a rise in prostate specific antigen (PSA) levels, all subjects had complete suppression of testosterone and luteinizing hormone (LH) levels. "Challenge tests" done in 8 patients with flutamide and a bolus of GnRH at 1 year demonstrated testosterone and LH concentrations at the lower limits of assay sensitivity. Suppression was observed for the duration of implant placement which was as long as 30 months in some patients. ${ }^{6}$ Similar results were reported in 27 additional subjects who received 4 implants, 2 implants, or a single implant. Implants were replaced on an annual basis. All patients had suppression of LH and testosterone during the treatment except 1 patient who had a rise of $\mathrm{LH}$ but continued suppression of testosterone and PSA. ${ }^{7}$

A phase III, open-label, fixed-dose multicenter study of 138 men with advanced prostate cancer was subsequently conducted. By week 4 after implantation, all subjects with baseline measurable testosterone levels had suppressed levels. PSA and LH levels were also suppressed. One hundred and ten patients underwent reimplantation after 52 weeks and were followed for 60 weeks. A surge in LH or testosterone levels was not seen with reimplantation. ${ }^{8}$ A subset of these patients participated in pharmacokinetic assessments. Peak histrelin concentrations were achieved rapidly (median time to peak was 12 hours) followed by a slow decline in levels over the 52-week time period. Overall, the implant demonstrated consistent drug delivery with a mean serum histrelin concentration of $0.265 \mathrm{ng} / \mathrm{mL}$.

The results of these studies led investigators to propose the development of a similar implant for use in children for the treatment of central precocious puberty. A $50 \mathrm{mg}$ histrelin hydrogel implant designed to release $65 \mu \mathrm{g}$ daily was subsequently developed. Figure 1 demonstrates the appearance and size of the histrelin subcutaneous implant, while existing studies using this device for the treatment of CPP are reviewed below.

\section{Studies in children}

A pilot study investigated the use of this implant in eleven girls with central precocious puberty who were already being treated with standard GnRHa therapy. Mean age at time of implant was 8.5 years (range 3.75-11), and each patient received 1 or 2 implants. Five girls had implants replaced at 9 months with a new implant placed at the same site. Six girls had implants left in place for 15 months. Participants were seen at 3-month intervals and GnRH-stimulation tests were done at the 6- and 9-month visits in all patients and at 12- and 15-month visits for those followed for 15 months. All patients had clinical evidence of good treatment response, and all had consistently suppressed basal and stimulated gonadotropins and estradiol. No differences were seen in girls treated with 1 vs 2 of the implants. ${ }^{4}$

This study was followed by a multicenter, open-label, prospective study to further evaluate the safety and efficacy of the histrelin subcutaneous implant for the treatment of CPP. Thirty-six subjects with CPP, including 20 treatment-naïve and 16 previously treated patients, were followed for 1 year after placement of the histrelin implant. Both treatment groups demonstrated significantly decreased peak stimulated LH concentrations at one month. Suppression ( $\mathrm{LH}<4 \mathrm{mIU} / \mathrm{mL}$ ) was maintained throughout the 12 months. In addition, the rate of skeletal maturation,

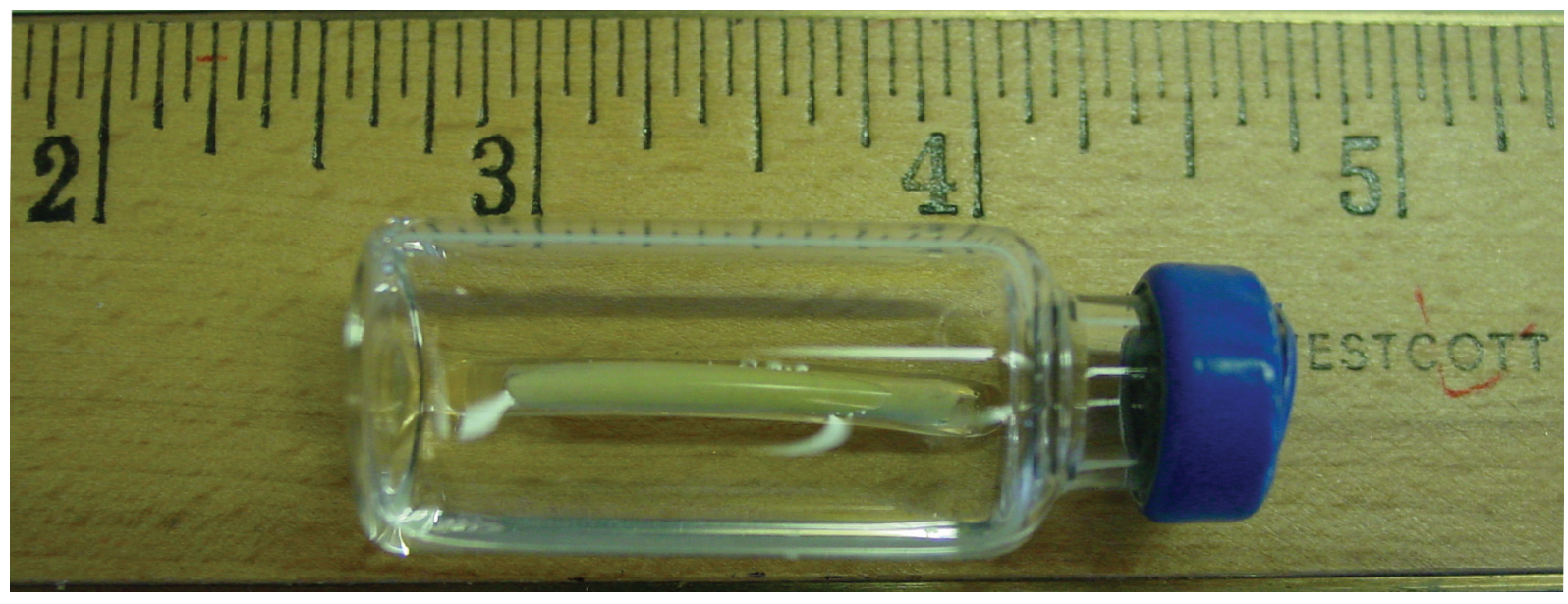

Figure I Appearance and size of the histrelin subcutaneous implant. Numbers on the ruler represent I-inch markings $(\mathrm{I}$ inch $=25 \mathrm{~mm})$. 
as assessed by the ratio of bone age to chronological age, declined significantly over the 12 months. Secondary sexual characteristics as described by Tanner staging did not progress in either group. Predicted adult height did not change in either group after one year. ${ }^{9}$ The results of this study led to FDA approval of the implant for treatment of CPP in children in May 2007.

Results from a second year of treatment in 31 subjects who elected to receive a new histrelin implant for continued treatment of CPP have also been reported. Of these subjects, 29 were girls and 18 were treatment naïve at the time of the initial histrelin implantation. Peak stimulated LH declined further from 12 to 24 months in both the treatment naïve and previously treated patients. Predicted adult height improved in girls from 12 months to 24 months $(156.3 \mathrm{~cm}$ to $158.4 \mathrm{~cm}$ $[\mathrm{p}=0.007]) .{ }^{10}$ Results from studies conducted in children with CPP are summarized in Table 1.

\section{Safety and tolerability}

The most common adverse events in children treated with the histrelin implant relate directly to the implant insertion or removal. Implant site reactions such as pain and bruising at the time of implantation are reported in up to $61 \%$ of patients. ${ }^{9,10}$ In the pilot study, there was 1 case each of a minor local infection requiring antibiotic therapy, inadvertent suture insertion into the implant, and implant extrusion 6 weeks after implantation. ${ }^{4}$ None of these problems have been noted in the subsequent studies, likely due to standardization of the implantation procedure. Difficulty with implant removal has also been reported, including need for ultrasound localization and breakage of the implant during explantation. ${ }^{9}$ Scarring (one keloid) at the site of the implant was reported in 2 patients in the 2-year study. ${ }^{10}$ There have been no reported significant abnormalities in hematology parameters, urinalysis, or other clinical laboratory evaluations. ${ }^{4,9}$ In 4 subjects who were treated for 12 months and evaluated 1 month after removal of the implant, histrelin levels were undetectable, and stimulated LH values had risen to pubertal ranges. ${ }^{9}$

Clinical studies indicate that the implant is well tolerated by patients. Reduced pain or discomfort and less disruption of activities as compared with depot GnRHa was noted by a quality of life questionnaire in the pilot study. ${ }^{4}$ In addition, 31 of 32 patients continuing on GnRHa therapy chose to receive a second implant after 12 months in the phase III trial. ${ }^{9}$ The appearance of a typical scar 6 months after implantation is seen in Figure 2.

\section{Costs and barriers to access}

The average wholesale price of the histrelin implant is US\$16,800. ${ }^{11}$ The cost related to placement and removal of the histrelin implant is not included in this price. Cost of these procedures varies depending on the clinical setting and type of anesthesia utilized. In our center at Indiana University

Table I Results of studies of the histrelin implant for the treatment of central precocious puberty

\begin{tabular}{|c|c|c|c|c|c|}
\hline Study & $\begin{array}{l}\text { Number of } \\
\text { patients }\end{array}$ & $\begin{array}{l}\text { Peak stimulated LH } \\
\text { results }(\mathrm{mlU} / \mathrm{ml})\end{array}$ & $\begin{array}{l}\text { Radiographic } \\
\text { findings }\end{array}$ & $\begin{array}{l}\text { Growth velocity } \\
\text { SDS }\end{array}$ & Adverse events \\
\hline Pilot study ${ }^{4}$ & II (all girls) & $\begin{array}{l}\text { Baseline I.3 } \pm \mathrm{I} .34 \\
6 \text { mo } 0.2 \pm 0.06^{*} \\
9 \text { mo } 0.25 \pm 0.08^{*} \\
12 \text { mo } 0.28 \pm 0.08^{*} \\
24 \text { mo } 0.25 \pm 0.08^{*}\end{array}$ & $\begin{array}{l}\text { BA-CA: } \\
\text { Baseline } 1.7 \pm 0.5 \\
9 \text { mo } 0.6 \pm 0.4\end{array}$ & $\begin{array}{l}\text { Baseline } 2.8 \pm 1.7 \\
9 \mathrm{mo}-3.1 \pm 2.2\end{array}$ & $\begin{array}{l}\text { Minor local infection }(I) \\
\text { Suture inserted into implant (I) } \\
\text { Spontaneous extrusion at } \\
6 \text { weeks (I) }\end{array}$ \\
\hline Phase III study 9 & $\begin{array}{l}36 \text { (33 girls) } \\
\text { (20 naïve) }\end{array}$ & $\begin{array}{l}\text { Naïve group } \\
\text { Baseline } 28.2 \pm 20 \\
\text { I mo } 0.8 \pm 0.4^{*} \\
\text { Pretreated group } \\
\text { Baseline } 2.1 \pm 2.1 \\
\text { I mo } 0.5 \pm 0.3^{*}\end{array}$ & $\begin{array}{l}\Delta(\mathrm{BA} / \mathrm{CA}) \\
\text { Baseline to } \\
\text { I } 2 \text { months: Naïve } \\
\text { group }-0.08 \pm 0.08^{*} \\
\text { Pretreated group } \\
-0.09 \pm 0.06^{*} \\
\text { All }-0.08 \pm 0.07^{*}\end{array}$ & $\begin{array}{l}\text { Naïve group } \\
12 \text { mo }-1.8 \pm 2.5 \\
\text { Pretreated group } \\
12 \text { mo } 0.6 \pm 2.3\end{array}$ & $\begin{array}{l}\text { Implant site reactions (I8) } \\
\text { Implant broken upon removal } \\
\text { (7) Ultrasound localization } \\
\text { needed for removal (I) }\end{array}$ \\
\hline Two-year results ${ }^{10}$ & $\begin{array}{l}31 \text { ( } 29 \text { girls) } \\
\text { (18 naïve) }\end{array}$ & $\begin{array}{l}\text { Naïve } \\
12 \text { mo } 0.92 \pm 0.58 \\
24 \text { mo } 0.5 \mathrm{I} \pm 0.33^{*} \\
\text { Pretreated group } \\
12 \text { mo } 0.74 \pm 0.50 \\
24 \text { mo } 0.45 \pm 0.35^{*}\end{array}$ & $\begin{array}{l}\Delta(\mathrm{BA} / \mathrm{CA}) \\
\text { I } 2 \text { to } 24 \text { months: } \\
-0.07 \pm 0.04^{*}\end{array}$ & $\begin{array}{l}12 \mathrm{mo}-0.42 \pm 2.4 \\
24 \mathrm{mo}-\mathrm{I} .75 \pm 3.05^{*}\end{array}$ & $\begin{array}{l}\text { Implant site reactions (19) } \\
\text { Ultrasound localization needed } \\
\text { for removal (3) Breakage upon } \\
\text { removal (5) Scar ( } 2 \text { reported, } \\
\text { I keloid) }\end{array}$ \\
\hline
\end{tabular}

*statistically significant change from baseline $(\mathrm{P}<0.05)$.

Abbreviations: BA, bone age; CA, chronological age; LH, luteinizing hormone; SDS, standard deviation score; $\triangle(B A / C A)$, change in ratio of bone age to chronological age. 


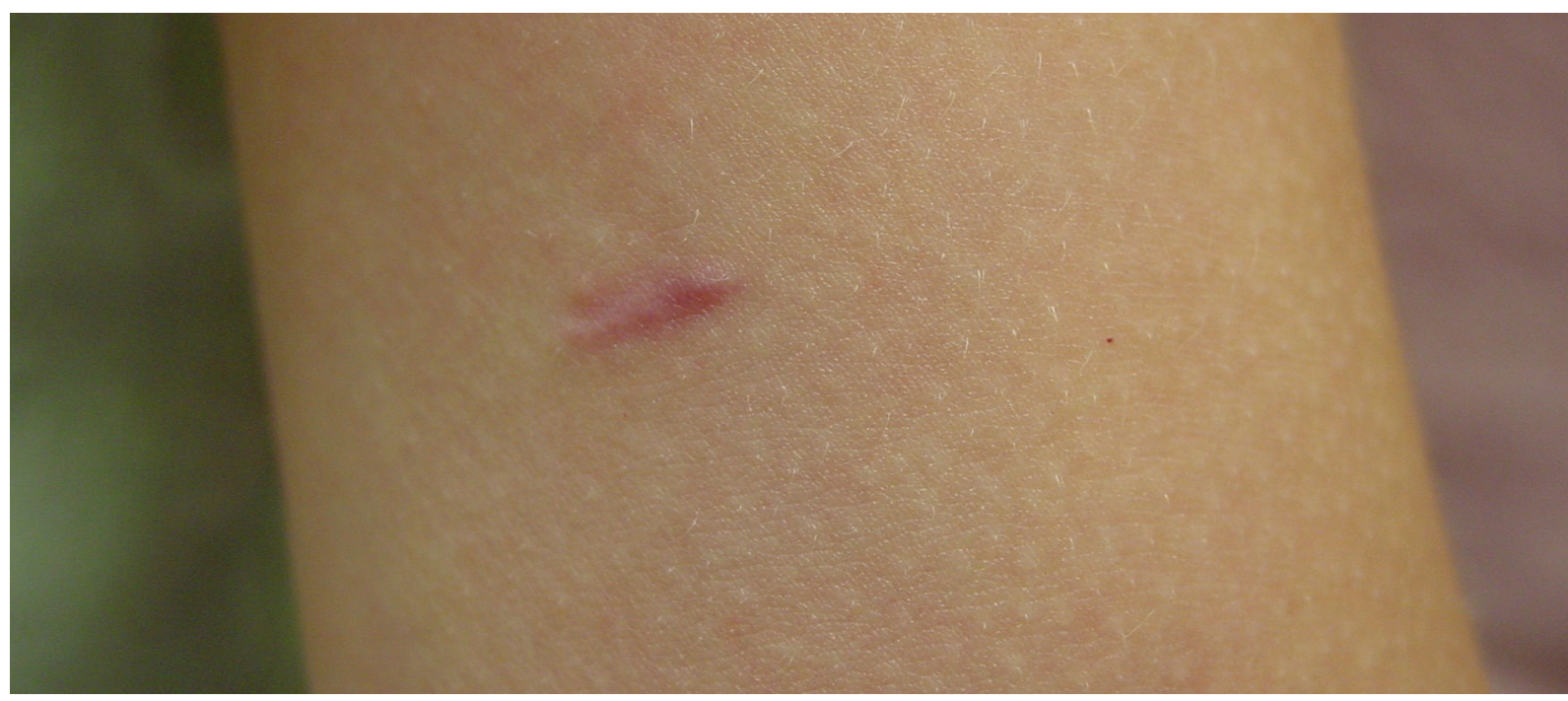

Figure 2 Appearance of typical scar seen 6 months after implantation of histrelin implant.

the implants are placed by a pediatric surgeon in a outpatient clinic setting with use of local anesthesia and distraction techniques. Conscious sedation and general anesthesia have been utilized at other medical centers. ${ }^{9}$ Certainly, the cost of implantation would be expected to be higher using these means of anesthesia.

By comparison, the average wholesale of depot leuprolide ranges from approximately US $\$ 8,936$ to $\$ 17,868$ annually depending on the dose required to obtain adequate suppression. ${ }^{11}$ These figures do not take into account the costs related to administration of the medication, the cost of potential time lost from work for parents and guardians due to frequent visits for medication administration, or the cost of transportation for these visits.

Insurance coverage varies by plan and requires prior authorization. In our experience at Riley Hospital for Children, private insurance companies have generally been willing to offer comparable coverage of the implant to depot leuprolide injections after consideration of the comparative costs between the two treatments and the problematic issues that can arise from the need for depot leuprolide injections every 3 to 4 weeks. These issues include non-compliance, patient discomfort from the injections, and additional costs related to administration as described previously. In contrast, Indiana Medicaid has balked at approving the implant device.

\section{Unanswered questions}

Additional issues yet to be addressed about the use of the histrelin implant for CPP include questions about the long term effects of this treatment option. While the implant has demonstrated safety and efficacy in the studies to date, it is possible that undesirable treatment effects may emerge in the future.

Concerns regarding long term reproductive function after treatment with GnRHa have been addressed by multiple investigators with biochemical demonstration of reversibility of HPG suppression by one year after discontinuation of therapy. ${ }^{12-14}$ With the profound suppression of peak LH levels seen in patients treated with the histrelin implant, concerns that the HPG axis could be oversuppressed have been raised. Based on the recovery of LH levels to the pubertal range after removal of the one year histrelin implant in the 4 patients who discontinued GnRHa treatment in the phase III trial, it seems unlikely that patients would be at increased risk for long term reproductive problems.

Another possible concern related to extreme hypothalamicpituitary-gonadal axis suppression is a theoretical detrimental effect on growth velocity. At present, the degree of suppression needed to achieve optimal benefit in terms of height is unknown. ${ }^{15}$ While the observed improvement in predicted adult height after 2 years of treatment with the histrelin implant is reassuring, long term follow-up to final adult height is needed to fully address this issue.

Children treated with GnRHa therapy often have increased body mass index (BMI), often prior to GnRHa therapy. This can progress to frank obesity in some patients $^{12}$ although GnRHa treatment in general has not been found to cause or aggravate obesity. ${ }^{16}$ Interestingly, in the 2-year results with the histrelin implant, mean BMI 
declined over the 12 - to 24 -month treatment period. ${ }^{10}$ Further study will be needed to assess whether this may be a particular treatment advantage related to this form of GnRHa therapy.

Another area for further investigation deals with the issue of implantation by non-surgical practitioners. Implant placement requires only a small incision, and then a specifically designed trocar allows for placement of the hydrogel capsule under the skin. Non-surgical practitioners could be trained to perform the procedure in the office setting. While this might reduce the cost of having the implant placed, it is possible that an increased incidence of implant site adverse reactions may be seen if non-surgical practitioners with less procedural experience perform the implantation. Similar questions should be addressed about the removal process as well.

\section{Conclusion}

Results from studies to date support the use of the histrelin implant as a safe, effective, and well-tolerated option for the treatment of children with CPP. Further study will provide additional information about long term safety and effectiveness and may be useful in providing solutions to overcome barriers to treatment.

\section{Disclosures}

Dr Eugster is a member of an advisory board and participates in clinical trials sponsored by Indevus.

\section{References}

1. Nebesio TD, Eugster EA. Current concepts in normal and abnormal puberty. Curr Probl Pediatr Adolesc Health Care. 2007;37(2):50-72.

2. Pescovitz OH, Comite F, Hench K, et al. The NIH experience with precocious puberty: diagnostic subgroups and response to short-term luteinizing hormone releasing hormone analogue therapy. $J$ Pediatr. 1986;108(1):47-54.
3. Klein KO, Barnes KM, Jones JV, Feuillan PP, Cutler GB, Jr. Increased final height in precocious puberty after long-term treatment with LHRH agonists: the National Institutes of Health experience. J Clin Endocrinol Metab. 2001;86(10):4711-4716.

4. Hirsch HJ, Gillis D, Strich D, et al. The histrelin implant: a novel treatment for central precocious puberty. Pediatrics. 2005;116(6): e798-802.

5. Dineen MK, Tierney DS, Kuzma P, Pentikis HS. An evaluation of the pharmacokinetics and pharmacodynamics of the histrelin implant for the palliative treatment of prostate cancer. J Clin Pharmacol. 2005;45(11):1245-1249.

6. Chertin B, Spitz IM, Lindenberg T, et al. An implant releasing the gonadotropin hormone-releasing hormone agonist histrelin maintains medical castration for up to 30 months in metastatic prostate cancer. J Urol. 2000;163(3):838-844.

7. Schlegel PN, Kuzma P, Frick J, et al. Effective long-term androgen suppression in men with prostate cancer using a hydrogel implant with the GnRH agonist histrelin. Urology. 2001;58(4):578-582.

8. Schlegel PN. Efficacy and safety of histrelin subdermal implant in patients with advanced prostate cancer. $J$ Urol. 2006;175(4):1353-1358.

9. Eugster EA, Clarke W, Kletter GB, et al. Efficacy and safety of histrelin subdermal implant in children with central precocious puberty: a multicenter trial. J Clin Endocrinol Metab. 2007;92(5):1697-1704.

10. Rahhal S CW, Kletter GB, Lee PA, et al. Results of a second year of therapy with the 12 month histrelin implant for the treatment of central precocious puberty. 2008; Abstract for oral presentation at the Pediatric Academic Society Annual Meeting.

11. Olsen J. New Drug Bulletin: Histrelin (Supprelin LA - Indevus). Available from http://uuhsc.utah.edu/pharmacy/bulletins/NDB_153.pdf.

12. Feuillan PP, Jones JV, Barnes K, Oerter-Klein K, Cutler GB, Jr. Reproductive axis after discontinuation of gonadotropin-releasing hormone analog treatment of girls with precocious puberty: long term follow-up comparing girls with hypothalamic hamartoma to those with idiopathic precocious puberty. J Clin Endocrinol Metab. 1999;84(1):44-49.

13. Bertelloni S, Mul D. Treatment of central precocious puberty by GnRH analogs: long-term outcome in men. Asian J Androl. 2008;10(4):525-534.

14. Bertelloni S, Baroncelli GI, Ferdeghini M, Menchini-Fabris F, Saggese G. Final height, gonadal function and bone mineral density of adolescent males with central precocious puberty after therapy with gonadotropinreleasing hormone analogues. Eur J Pediatr. 2000; 159(5):369-374.

15. Kunz GJ, Sherman TI, Klein KO. Luteinizing hormone (LH) and estradiol suppression and growth in girls with central precocious puberty: is more suppression better? Are pre-injection LH levels useful in monitoring treatment? J Pediatr Endocrinol Metab. 2007;20(11):1189-1198.

16. Carel JC EE, Rogol A, Ghizzoni L, Palmert M. on behalf of the ESPELWPES GnRH analogs consensus conference group. Consensus statement on the use of GnRH analogs in children. Pediatrics. In press. 
